\title{
ANALISIS RUMUSAN VISI, MISI, DAN TUJUAN PENDIDIKAN ANAK USIA DINI DI TK II PERTIWI
}

\author{
Safira Zulfania \\ Universitas Islam Negeri Sunan Kalijaga Yogyakarta \\ Email: safirazulfania95@gmail.com
}

\begin{abstract}
This research wanted to know the planning of the management of the vision, mission, and goals of the school in TK II Pertiwi Semarang. Choosing this kindergarten because the school institution has the appropriate vision, mission and goals. This research is descriptive research, namely research defines how the management of the vision, mission, and goals of TK II Pertiwi Semarang. The data obtained using qualitative research, data collection techniques can be done through observation and interviews. In preparing the vision and mission, it involves elements of the surrounding community and the management of related institutions. Pertiwi Kindergarten II School based on the vision, mission and objectives already includes the existing criteria. There needs to be an evaluation if there is anything that needs to be improved.
\end{abstract}

Key words: planning; management; TK II Pertiwi

\begin{abstract}
Abstrak: Penelitian ini ingin mengetahui perencanaan pengelolaan visi, misi, dan tujuan sekolah di TK II Pertiwi Semarang. Memilih TK ini karena lembaga sekolah yang memiliki visi, misi dan tujuan yang sesuai. Penelitian ini deskriptif, yaitu penelitian mengartikan bagaimana pengelolaan visi, misi, dan tujuan TK II Pertiwi Semarang. Data yang diperoleh menggunakan penelitian kualitatif, teknik pengumpulan data dapat dilakukan melalui observasi, dan wawancara. Dalam penyusunan visi dan misi melibatkan element masyarakat sekitar dan pengurus lembaga yang terkait. Sekolah TK II Pertiwi berdasarkan visi, misi dan tujuan sudah mencakup kriteria yang ada. Perlu adanya evaluasi jika ada sekiranya yang perlu diperbaiki.
\end{abstract}

Kata kunci: perencanaan; pengelolaan; TK II Pertiwi

\section{PENDAHULUAN}

Pendidikan menjadi tonggak dalam memberikan pengaruh penting dalam melihat dunia yang semakin berkembang terutama di era digital sekarang ini. Menjadi penerus bangsa yang berkakhlak mulia dalam Tindakan dan cakap maka membutuhkan adanya berbagai keberagaman bangsa yang memiliki karakteristik dan keunikan tersendiri antara lain geografis, potensi sumber daya, sarana dan prasarana, kondisi sosial 
Safira Zulfania, Analisis Rumusan Visi, Misi, dan Tujuan Pendidikan Anak Usia Dini di TK II Pertiwi

budaya, dan keberagaman lainya yang terdapat di setiap daerah. Melalui pendidikan yang merata di setiap daerah diharapkan mereka terampil dengan berbagai problem yang ada maupun tantangan bangsa di masa depan. Maka dibutuhkan seperangkat alat canggih yang pada eranya salah satunya melalui lembaga pendidikan. Pentingnya satuan pendidikan yang merata di setiap daerah, maka diperlukan kurikulum sebagai tongkat pendidikan agar dapat dikembangkan dan diterapkan secara langsung pada lembaga pendidikan.

Banyaknya lembaga PAUD yang memiliki visi, misi, tujuan, dan juga program yang sesuai dengan konsep sekolah. Kesuksesan sebuah lembaga tidak hanya pada rencana yang telah disusun, tetapi juga keberhasilan dalam menjalankan program tersebut. Sehingga program yang sudah disusun dapat berjalan sesuai rencana yang telah dirumuskan. ${ }^{1}$

Menurut teori Midle tentang teori pengelolaan sebagai proses perencanaan, pengorganisasian, pengarahan, dan pengendalian". Tugas seorang pengelola, menyusun struktur penting dalam memberikan arahan untuk kemajuan sekolah kedepannya. Maka dari itu seorang pengelola mampu merencakanan visi, misi dan tujuan sekolah yang diharapkan.

Pengelolaan yang kurang optimal disebabkan karena pendirian Pendidikan anak usia dini yang terlalu cepat sehingga tidak akan dapat memberikan dampak pada wilayah sekitar yang sudah mengharapkan segera di buka menjadi tertunda karena ada beberapa masalah. ${ }^{2}$

Pendidikan Anak Usia Dini terkait dengan visi, misi dan tujuan lembaga pendidikan anak usia dini yang sudah diatur dalam Permendikbud Nomor 146 Tahun 2014 tentang Kurikulum 2013 Pendidikan Anak Usia Dini, di dalam dokumen 1 KTSP PAUD berisi visi, misi, dan tujuan satuan

\footnotetext{
${ }^{1}$ Suhaini. Jurnal Qurroti: Jurnal Pendidikan Islam Anak Usia Dini, Vol. 2 No.1 April 2020 Yogyakarta: UIN Sunan Kalijaga. 2020.

${ }^{2}$ Amirul Mukminin. 2017. Pengelolaan pendidikan anak usia dini pemula, Journal of Nonformal Education, Semarang: Universitas Negeri Semarang UNNES.
} 
pendidikan. Dalam Permendikbud 146 tahun 2014 tentang pedoman pengembangan kurikulum tingkat satuan pendidikan anak usia dini. Visi tersebut mampu memberikan inspirasi, motivasi, dan kekuatan pada warga satuan pendidikan dan segenap pihak yang berkepentingan. Visi dapat ditinjau dan dirumuskan kembali secara berkala sesuai dengan perkembangan dan tantangan di masyarakat. ${ }^{3}$

Misi adalah sesuatu yang harus dilaksanakan sebagai penjabaran visi yang telah ditetapkan dalam kurun waktu tertentu untuk menjadi rujukan bagi penyusunan program serta memberikan keluwesan dan ruang gerak pengembangan kegiatan satuan pendidikan yang terlibat, dengan berdasarkan masukan dari seluruh warga satuan pendidikan anak usia dini. Misi dapat ditinjau dan dirumuskan kembali secara berkala sesuai dengan perkembangan dan tantangan di masyarakat. Selanjutnya, tujuan merupakan penjabaran dari visi dan misi yang juga merupakan suatu target yang ingin dicapai atau dihasilkan oleh suatu organisasi atau lembaga tertentu. Satuan Pendidikan merumuskan tujuan berdasarkan visi dan misi yang ditetapkan.

Sekolah menjadi salah satu lembaga pendidikan yang memiliki tugas untuk menciptakan tujuan pendidikan nasional mampu menjalankan peran sebagai lembaga pendidikan, sekolah harus dikelola dengan baik agar dapat menciptakan pendidikan yang sudah disusun dengan ideal. Pengelolaan sekolah yang yang kurang baik maka akan menghambat proses pendidikan yang ada dan dapat menghambat strategi sekolah dalam menjalankan sebagaimana mestinya lembaga pendidikan formal. Supaya pengelolaan sekolah dapat berjalan dengan baik, maka dibutuhkan

\footnotetext{
${ }^{3}$ Kemendikbud. 2014. "PERMENDIKBUD No. 146 Tahun 2014 Tentang Kurikulum 2013 Pendidikan Anak Usia Dini." Permen Kemendikbud 2025 (1679).
} 
Safira Zulfania, Analisis Rumusan Visi, Misi, dan Tujuan Pendidikan Anak Usia Dini di TK II Pertiwi

persiapan strategis dengan upaya pengendalian sekolah yang efektif dan efisien sehingga tujuan dan sasarannya terpenuhi. ${ }^{4}$

Berdasarkan uraian diatas diketahui pentingnya perencanaan pengelolaan di sekolah pendidikan anak usia dini dan lebih tepatnya di Taman Kanak-Kanak. Peneliti akan menelusuri informasi dan membandingkan dengan teori yang tentang perencanaan pengelolaan di tempat Taman Kanak-kanak di Semarang. Sample yang peneliti ambil adalah di TK II Pertiwi Semarang. TK tersebut memiliki kelebihan dan kekurangan. TK II Pertiwi Semarang memiliki visi, misi, dan tujuan yang sudah dibentuk. TK II Pertiwi Semarang merupakan sekolah yang memiliki visi, misi dan tujuan yang berbeda dari beberapa sekolah di Semarang. Fokus penelitian ini pada penyusunan visi, misi, dan tujuan sekolah TK II Pertiwi Semarang.

\section{METODE PENELITIAN}

Jenis penelitian ini adalah deskriptif, yaitu penelitian mengartikan bagaimana pengelolaan visi, misi, dan tujuan TK II Pertiwi Semarang. Objek dari penelitian ini adalah perencanaan pengelolaan pendidikan anak usia dini di TK II Pertiwi. Perencanaan pengelolaan pendidikan anak usia dini yaitu visi, misi, dan tujuan. Penulis memilih objek penelitian tersebut karena lembaga TK tersebut menekankan nilai-nilai agama dan membiasakan beribadah sesuai agamanya. Lembaga pendidikan anak usia dini di TK II Pertiwi Semarang memiliki akreditasi lembaga "A".

Dalam penelitian kualitatif, teknik pengumpulan data dapat dilakukan melalui observasi dan wawancara. Pada penelitian ini teknik pengumpulan data adalah sebagai berikut:

\footnotetext{
${ }^{4}$ Ahmad Calam, Amnah Qurniati. Jurnal IImiah Saintikom, Vol. 15, No. 1, Januari Yogyakarta: UIN Sunan Kalijaga. 2016.
} 
a. Observasi melalui observasi peneliti datang di lembaga yang diteliti. Teknik ini dilakukan oleh peneliti untuk mengamati perencanaan pengelolaan di TK. Unsur yang akan diamati meliputi visi, misi dan tujuan perencanaan pengelolaan yang telah disusun.

b. Wawancara yang dilakukan dalam penelitian ini adalah wawancara semi terstruktur. Wawancara tersebut dapat dilakukan dengan bebas. Teknik ini dilakukan peneliti untuk menggali perencanaan pengelolaan yang telah disusun. Adapun pokok dalam wawancara meliputi apa visi, misi, dan tujuan di lembaga itu; apakah guru memahami visi, misi, dan tujuan; bagaimana cara guru mewujudkan visi, misi, dan tujuan.

Wawancara yang fokus dengan responden dilakukan dalam bentuk tanya jawab dan diskusi yang mengarah pada fokus penelitian. Melakukan wawancara diusahakan agar tidak sampai terjadi perubahan pada tindakan dan cara subjek penelitian terjadi kehadiran peneliti atau tanpa di sadari oleh subjek bahwa sesungguhnya dirinya sedang diwawancarai. ${ }^{5}$ c. Audio yang dilakukan dalam penelitian ini adalah merupakan isi suara yang diambil saat wawancara. Audio ini untuk memudahkan peneliti dalam mendukung adanya fakta suara langsung dari kepala dan guru.

\section{KERANGKA TEORI}

Visi adalah idelitas akan masa depan lembaga PAUD yang akan didirikan. Visi merupakan rencana yang ingin dicapai dimasa datang, dari visi inilah semua komponen lain akan menuju ke satu titik tujuan, yaitu mencapai visi tersebut. Misi sendiri diartikan sebagai bentuk uraian dari visi yang berupa langkah-langkah strategi-strategi yang unggul untuk merealisasikan visi lembaga. ${ }^{6}$

\footnotetext{
${ }^{5}$ Ratna Pangastuti. Studi Analisis Manajemen Pengelolaan Kelas di TPA, Vol. 2 No. 2, 2017. Surabaya: UIN Sunan Ampel Surabaya.

${ }^{6}$ Suyadi. Manajemen PAUD, (Yogyakarta: Pustaka Pelajar, 2011), hal 45-46.
} 
Safira Zulfania, Analisis Rumusan Visi, Misi, dan Tujuan Pendidikan Anak Usia Dini di TK II Pertiwi

Adapun data dari visi, misi dan tujuan di TK II Pertiwi visi,misi, dan tujuan, wawancara yang dilakukan peneliti pada kepala sekolah maupun guru bahwa visi, misi dan tujuan dari sekolah TK II Pertiwi Semarang.

a. Visi

Terwujudnya anak usia dini yang sehat, cerdas, mandiri, berakhlakmulia dan bertaqwa

b. Misi

1. Memberikan pengasuhan, pelayanan bagi anak usia dini

2. Mendidik anak secara optimal sesuai dengan kemampuan anak

3. meleyakkan dasar ketaqwaan dengan membiasakan beribadah sesuai tuntunan agama

4. Menyiapkan anak didik kejenjang sekolah dasar

5. menciptakan suasana belajar yang kondusif dan menyenangkan

c. Tujuan

Membentuk generasi yang berakhlak mulia melalui pembelajaran yang menyenangkan sehingga anak mandiri dan dapat menyesuaikan diri terhadap lingkungannya.

Adapun dalam dokumen I KTSP PAUD pada Permendikbud 146 tahun 2014 yang tentukan oleh satuan pendidikan anak usia dini

a. Visi adalah cita-cita bersama pada masa mendatang dari warga satuan pendidikan anak usia dini, yang dirumuskan dan ditetapkan oleh setiap lembaga berdasarkan masukan dari seluruh warga lembaga pendidikan anak usia dini. Visi tersebut mampu memberikan inspirasi, motivasi, dan kekuatan pada warga satuan pendidikan dan segenap pihak yang berkepentingan. Visi dapat ditinjau dan dirumuskan kembali secara berkala sesuai dengan perkembangan dan tantangan di masyarakat. ${ }^{7}$ b. Misi satuan pendidikan

${ }^{7}$ Kemendikbud. 2014. "PERMENDIKBUD No. 146 Tahun 2014 Tentang Kurikulum 2013 Pendidikan Anak Usia Dini." Permen Kemendikbud 2025 (1679). 
Misi adalah sesuatu yang harus dilaksanakan sebagai penjabaran visi yang telahditetapkan dalam kurun waktu tertentu untuk menjadi rujukan bagi penyusunan program serta memberikan keluwesan dan ruang gerak pengembangan kegiatan satuan pendidikan yang terlibat, dengan berdasarkan masukan dari seluruh warga satuan pendidikan anak usia dini. Misi dapat ditinjau dan dirumuskan kembali secara berkala sesuai dengan perkembangan dan tantangan di masyarakat.

c. Tujuan satuan pendidikan

satuan pendidikan merumuskan tujuan berdasarkan visi dan misi yang ditetapkan.

Visi memiliki peran penting dalam menentukan arah kebijakan dan karakteristik setiap lembaga. Adapun beberapa cakupan yang perlu diperhatikan dalam merumuskan yang baik, antara lain:

1. Visi sekolah berorientasi ke masa depan, untuk jangka waktu yang lama (bila perlu dibuat jangka waktunya).

2. Menunjukkan keyakinan masa depan yang jauh lebih baik, sesuai dengan norma dan harapan masyarakat.

3. Visi sekolah harus mencerminkan standar keunggulan dan cita-cita yang ingin di capai.

4. Visi sekolah harus mencerminkan dorongan yang kuat akan tumbuhnya inspirasi, semangat dan komitmen bagi stakeholder.

5. Mampu menjadi dasar dan mendorong terjadinya perubahan dan pengembangan sekolah kearah yang lebih baik.

Misi sebagai tindakan untuk mewujudkan visi. Misi merupakan penafsiran dari visi dalam bentuk rumusan, kewajiban dan rancangan 
Safira Zulfania, Analisis Rumusan Visi, Misi, dan Tujuan Pendidikan Anak Usia Dini di TK II Pertiwi

tindakan sebagai arah untuk mewujudkan visi. Adapun yang perlu diperhatikan dalam merumuskan misi sekolah antara lain:8

1. Pernyataan misi sekolah harus menunjukan secara jelas mengenai apa yang hendak dicapai oleh sekolah.

2. Rumusan misi sekolah selalu dalam bentuk kalimat yang menunjukkan "tindakan" dan bukan kalimat yang menunjukkan "keadaan" sebagai mana pada rumusan visi.

3. Satu indikator visi dapat dirumuskan lebih dari satu rumusan misi. Antara indikator visi dengan rumusan misi atau ada keterkaitan atau terdapat benang merahnya secara jelas.

4. Misi sekolah menggambarkan tentang produk atau pelayanan yang akan diberikan masyarakat (siswa).

5. Kualitas produk atau layanan yang ditawarkan harus memiliki daya saing yang tinggi, namun disesuaikan dengan kondisi sekolah.

Visi dan misi merupakan cakupan yang sangat penting dalam sekolah, visi dan misi digunakan pada saat pengoprasionalkan dapat bergerak sesuai yang diinginkan oleh semua kelompok lembaga, dengan harapan dapat mencapai sesuai yang diinginkan dimasa mendatang.

Dalam artikel Suhaini, setiap lembaga pasti sudah memiliki tujuan. Pada satuan lembaga PAUD tujuan menjadi bagian tidak terpisahkan dari visi dan misi. Jika visi dan misi sudah ditetapkan, maka visi dan misi harus masuk ke dalam tujuan, tujuan PAUD tersebut menjadi sasaran dan harapan yang harus dicapai oleh semua sekolah PAUD. Dalam Peraturan Menteri pendidikan Nasional Nomor 19 Tahun 2007 tentang Standar Pengelolaan Pendidikan oleh Satuan Pendidikan Dasar dan Menengah

${ }^{8}$ Ahmad Calam, Merumuskan Visi dan Misi lemabag Pendidikan, Jurnal IImiah Saintikom, Vol 15. No. 1, 2016. 
menganjurkan acuan dalam merumuskan dan menetapkan beserta mengembangkan tujuan sekolah, sebagai berikut:

1. Mendeskripsikan kadar kualitas yang harus diterapkan dalam jangka menegah (empat tahunan).

2. Berpedoman pada visi dan misi dan juga tujuan pendidikan nasional yang relevan dengan kebutuhan masyarakat.

3. berpedoman pada standar kompetensi lulusan yang sudah dilaksanakan oleh sekolah dan pemerintah.

4. Disosialisasikan kepada warga sekolah dan seluruh pihak yang terkait.

Sebuah tujuan sekolah sebagai cita-cita di masa selanjutnya yang akan diwujudkan dan berpedoman pada penyusunan target dan strategi sekolah dalam mewujudkannya. Dalam merealisasikan tujuan yang efesien dapat menunjukkan kesiapan sekolah dalam mengalami perubahan dapat disikapi dengan positif, mengarah pada visi dan misi menjadi acuan dalm mengambil kebijakan. ${ }^{9}$

\section{TEMUAN DAN PEMBAHASAN}

Melalui hasil wawancara yang dilakukan, peneliti mendapatkan informasi bahwa visi,misi dan tujuan disusun oleh lembaga sendiri yang mengacu pada peraturan yang sudah ditetapkan di dalam Permendikbud Nomor 146 Tahun 2014 dalam dokumen 1 KTSP Paud. Sesuai dengan hasil yang wawancara bersama kepala sekolah bahwa dalam penyusunan visi, misi, dan tujuan bahwa pastinya dalam berkembangnya zaman setiap tahun pasti akan berubah juga merujuk pada visi, misi, dan tujuan dalam satuan pendidikan. Dalam mendasari Visi, misi dan tujuan di TK II Pertiwi melihat kebutuhan di lingkungan sekolah maupun dari pihak sekolah

${ }^{9}$ Suhaini. Jurnal Qurroti: Jurnal Pendidikan Islam Anak Usia Dini, Vol. 2 No.1 April 2020 Yogyakarta: UIN Sunan Kalijaga. 2020. 
Safira Zulfania, Analisis Rumusan Visi, Misi, dan Tujuan Pendidikan Anak Usia Dini di TK II Pertiwi

sendiri. Mewujudkan sekolah dengan visi, misi dan tujuan yang di harapkan lembaga disini dengan membentuk anak yang berakhlak dan membiasakan beribadah sesuai dengan tuntunan agama.

Hasil yang wawancara bersama guru sekolah bahwa dalam penyusunan visi, misi, dan tujuan bahwa pastinya dalam berkembangnya zaman setiap tahun pasti akan berubah juga merujuk pada visi, misi, dan tujuan dalam satuan pendidikan. Seorang guru pastinya memahami isi dari visi, misi dan tujuan TK II Pertiwi. Pendidik juga akan membentuk anak yang sesuai dengan visi, misi, dan tujuan yang diharapkan.

\section{KESIMPULAN}

Berdasarkan hasil penelitian dapat disimpulkan bahwa visi, misi, dan tujuan di TK II Pertiwi dengan penyusunan perlu kajian yang mendalam bukan hanya sekedar buat tanpa tahu dasar pembentukan visi, misi dan tujuan yang baik. Dalam penyusunan visi dan misi melibatkan element masyarakat sekitar dan pengurus lembaga yang terkait. Sekolah TK II Pertiwi berdasarkan visi, misi dan tujuan sudah mencakup kriteria yang ada. Perlu adanya evaluasi jika ada sekiranya yang perlu diperbaiki.

\section{DAFTAR PUSTAKA}

Calam, Ahmad. 2016. Amnah Qurniati. Jurnal IImiah Saintikom, Vol. 15, No. 1, Januari Yogyakarta: UIN Sunan Kalijaga.

Kemendikbud. 2014. "PERMENDIKBUD No. 146 Tahun 2014 Tentang Kurikulum 2013 Pendidikan Anak Usia Dini." Permen Kemendikbud 2025 (1679).

Marlina, Leny. 2017. Perencanaan Pembelajaran Pendidikan Anak Usia Dini, Palembang: UIN Raden Fatah.

Mukminin, Amirul. 2017. Pengelolaan pendidikan anak usia dini pemula, Journal of Nonformal Education, Semarang: Universitas Negeri Semarang UNNES. 
Pangastuti, Ratna. 2017. Studi Analisis Manajemen Pengelolaan Kelas di TPA, Vol. 2 No. 2. Surabaya: UIN Sunan Ampel Surabaya.

Peraturan Menteri Pendidikan dan Kebudayaan Republik Indonesia Nomor 137 Tahun 2014 Tentang Standar Nasional Pendidikan Anak Usia Dini, Sekretariat Negara Republik Indonesia, Jakarta

Suhaini. 2020. Jurnal Qurroti: Jurnal Pendidikan Islam Anak Usia Dini, Vol. 2 No. 1 April 2020 Yogyakarta: UIN Sunan Kalijaga.

Suyatni. 2015. Artikel Pengelolaan Program pendidikan anak usia dini pada kelompok bermain, Universitas Tanjungpura, Pontianak. 